\title{
Optical and Structural Studies of Sol-Gel Deposited Nanostructured CdO Thin Films: Annealing Effect
}

\author{
A. Abdolahzadeh Ziabari ${ }^{a}$ And F.E. Ghodsi ${ }^{a, b, *}$ \\ ${ }^{a}$ Department of Physics, Faculty of Science, Islamic Azad University, Lahijan Branch, P.O. Box 1616, Lahijan, Iran \\ ${ }^{b}$ Department of Physics, Faculty of Science, University of Guilan, Namjoo Av., P.O. Box 413351914, Rasht, Iran
}

(Received March 1, 2011; in final form April 19, 2011)

\begin{abstract}
Nanocrystalline $\mathrm{CdO}$ thin films were prepared by sol-gel dip-coating method using a different solution. The as-deposited films were subjected to drying temperature of $120^{\circ}$ in air. The prepared films were annealed in different temperatures of 200,300 and $400^{\circ} \mathrm{C}$. The characterization of samples was carried out by X-ray diffraction, scanning electron microscopy and UV-VIS spectroscopy. Results show that the samples are polycrystalline in nature and the crystallinity of the films improves with temperature. The average grain size is in the range of 19-34 nm. It was observed that the optical parameters of the films were affected by annealing temperature.
\end{abstract}

PACS: 78.20.Ci, 78.66.Li, 78.67.-n, 81.20.Fw

\section{Introduction}

Transparent conducting oxide thin films such as zinc oxide $(\mathrm{ZnO})$, indium tin oxide (ITO), tin oxide $\left(\mathrm{SnO}_{2}\right)$ and cadmium oxide $(\mathrm{CdO})$ are extensively used in semiconductor optoelectronic applications [1-3]. CdO is an $n$-type semiconductor with a rock-salt crystal structure (fcc) and possesses a direct band gap of $2.2 \mathrm{eV}$ [4]. Its high electrical conductivity (even without doping) and high optical transmittance in the visible region of solar spectrum along with a moderate refractive index make it useful for various applications such as solar cells, transparent electrodes, phototransistors, photodiodes, gas sensors, etc. [5, 6]. Undoped and doped $\mathrm{CdO}$ thin films have been prepared by various techniques such as spray pyrolysis [7], ion beam sputtering [8], sol-gel [9], magnetic sputtering [10], etc. Basically, works on heat treatment of $\mathrm{CdO}$ thin films have already been reported [11, 12] Several authors have reported triethanolamine as the stabilizer in methanol based sol-gel derived $\mathrm{CdO}$ thin films [11-13]. Monoethanolamine has also been used as the stabilizer with 2-methoxyethanol to prepare nanocluster $\mathrm{n}$-CdO thin films [14]. A literature survey indicated that surprisingly no report on diethanolamine stabilized sols exists.

In this study, undoped $\mathrm{CdO}$ thin films have been deposited by sol-gel dip-coating method using methanol and diethanolamine as the solvent and stabilizer respectively, and the temperature dependence of structural, morphological and optical properties of the films has been studied. We have chosen the dip-coating method because of easier composition control, better homogeneity, low processing temperature and lower cost.

* corresponding author; e-mail: feghodsi@guilan.ac.ir

\section{Experimental details}

\subsection{Preparations of thin films by sol-gel}

$\mathrm{CdO}$ thin films have been deposited on glass substrates using sol-gel dip-coating process. Cadmium acetate dehydrate $\left[\mathrm{Cd}\left(\mathrm{COOCH}_{3}\right)_{2} \cdot 2 \mathrm{H}_{2} \mathrm{O}\right]$ has been taken as the source cadmium. Diethanolamine $\left(\mathrm{C}_{4} \mathrm{H}_{11} \mathrm{NO}_{2}\right.$, DEA $)$ and methanol $\left(\mathrm{CH}_{4} \mathrm{O}\right)$ were used as a stabilizer and solvent, respectively. At first, cadmium acetate dehydrate of $0.5 \mathrm{M}$ were prepared. In order to prepare $\mathrm{CdO}$ precursor solution, DEA was dissolved initially in methanol. Subsequently, cadmium acetate dehydrate was added to the solution. In order to obtain a transparent solution, slow constant stirring is required. A solution consisting of methanol and glycerol was prepared separately, and finally added to the transparent solution. The resulting transparent solution was stirred constantly for $1 \mathrm{~h}$ at room temperature and aged for $24 \mathrm{~h}$. Before dip coating, the glass substrates were first degreased by detergent, rinsed thoroughly by deionized water and then in boiled water. In order to remove macroscopic contaminations, the substrates were cleaned ultrasonically in a mixture of ethanol and acetone (each of $50 \%$ in volume) for $15 \mathrm{~min}$. The latter procedure then was repeated in deionized water. At least, the substrates were immerged in acetone and rinsed with deionized water and dried with nitrogen. The cleaned substrates were dipped into the solution and withdrawn from it vertically at a speed of $\approx 116 \mathrm{~mm} / \mathrm{min}$. After the dip coating the film were dried at $120^{\circ} \mathrm{C}$ for $20 \mathrm{~min}$ in an oven to evaporate the solvent and for gel formation. This procedure was repeated 10 times, and finally the resulting thin films were subjected to an annealing process at temperatures of 200 to $400^{\circ} \mathrm{C}$ (at $100^{\circ} \mathrm{C}$ intervals).

\subsection{Characterization}

The structure of the prepared films was studied by the X-ray diffraction (XRD) method using a XRD6000, Shi- 
madzu system with $\mathrm{Cu} K_{\alpha}$ radiation $(0.15406 \mathrm{~nm})$. Surface morphology of the films was studied by scanning electron microscopy (SEM) with a VEGAII TESCAN instrument, the energy used was $30 \mathrm{kV}$. The optical transmittance spectra of the films were measured using a Varian Cary100 UV/Visible spectrophotometer. The optical constants of the films were calculated using pointwise unconstrained minimization algorithm (PUMA) and fitting the data to the Cauchy formula in thin films [15].

\section{Results and discussion}

\subsection{Structural and morphological properties}

Figure 1 shows the XRD pattern of the $\mathrm{CdO}$ thin films as-deposited and annealed at different annealing temperature. As-deposited film is almost not showing any diffraction peak around preferred orientation of $\mathrm{CdO}$. Three other patterns reveal polycrystalline films of $\mathrm{cu}-$ bic CdO structure of space group $F m 3 m$. The details of the crystalline structure (interplanar distance and lattice constant) of the films have been given in Table I. The lattice constant evaluated for the films was about $4.69 \AA$, which is almost identical with the standard value. The standard interplanar distances ( $d$-values) of $\mathrm{CdO}$ thin films are 2.71, 2.34 and 1.66 for diffraction peaks (111), (200), and (220), respectively. As it is clear from
Table I, there are very little differences between observed $d$-values and the standard $d$-values. These differences may arise from the defects which occur during the deposition. The observed diffraction peaks (111), (200), (220), and (311) for CdO thin films are in good agreement with the reported data [16]. It can be seen also that the prepared thin films are highly oriented in the (111) direction. In addition, from the XRD peak width, it is found that the peak width decreases as the annealing temperature increases. The average size of the grains has been calculated from the XRD pattern using the Sherrer formula [17]:

$$
D=\frac{0.94 \lambda}{\beta \cos \theta},
$$

where $D$ is the grain size, $\beta$ is the full width at half maximum (FWHM) of the preferential orientation diffraction peak and $\lambda$ is the wavelength of the $\mathrm{X}$-rays. The average grains size is in the range of $19-34 \mathrm{~nm}$. Table I lists the degree of FWHM and grain size of CdO thin films for different diffraction lines. Generally, the grain size increases with annealing temperature for different diffraction peaks. For the film annealed at $400^{\circ} \mathrm{C}$ the FWHM of the (111) diffraction peak gains a relatively lower value of $0.25^{\circ}$. The evaluated grain size of this film is about $34 \mathrm{~nm}$, suggesting a better crystallinity.

TABLE I

The FWHM (degree), the average grain size $D(\mathrm{~nm})$, the interplanar distance $d(\AA)$ and the lattice constant $a(\AA)$ of $\mathrm{CdO}$ thin films annealed at different temperatures for different diffraction lines.

\begin{tabular}{c|c|c|c|c|c|c|c|c|c|c|c|c}
\hline \hline \multirow{2}{*}{$\begin{array}{c}\text { Annealing } \\
\text { temperature }\left[{ }^{\circ} \mathrm{C}\right]\end{array}$} & \multicolumn{4}{|c|}{$(111)$} & \multicolumn{4}{c|}{$(200)$} & \multicolumn{4}{c}{$(220)$} \\
\cline { 2 - 26 } & FWHM & $D$ & $d$ & $a$ & FWHM & $D$ & $d$ & $a$ & FWHM & $D$ & $d$ & $a$ \\
\hline 200 & 0.45 & 19 & 2.70 & 4.70 & - & - & - & - & - & - & - & - \\
300 & 0.33 & 26 & 2.70 & 4.69 & 0.47 & 18 & 2.34 & 4.69 & 0.60 & 15 & 1.65 & 4.69 \\
400 & 0.25 & 34 & 2.71 & 4.69 & 0.29 & 30 & 2.34 & 4.69 & 0.57 & 17 & 1.66 & 4.69
\end{tabular}

Figure 2 shows the typical SEM micrographs of the $\mathrm{CdO}$ films annealed at 200 and $400{ }^{\circ} \mathrm{C}$ in air. The images confirm the results of X-ray diffraction pattern of the $\mathrm{CdO}$ thin films. As it is clear from Fig. 2 the crystallinity of the samples has been improved by annealing temperature. Furthermore, we can see that all the films have a high smooth and homogeneous surface morphology with spherical nanocrystalline grains, also all the films are dense and adhere well to the substrate without any cracks.

\subsection{Optical properties}

Figure 3 shows the optical transmittance spectra with wavelength from 300 to $800 \mathrm{~nm}$ of the $\mathrm{CdO}$ thin films annealed at different temperatures in air. We can ob- serve from Fig. 3 that all the films are transparent in the visible region. It can be seen also that the increase in transmittance in UV region is not sharp. This indicates that the absorption band gap transitions in the studied films are due to direct and indirect transitions [18]. Furthermore, we can distinguish from Fig. 3 that the optical transparency of the films decreases with increases in annealing temperature. In order to study the effects of annealing temperature, the fundamental absorption edge of the films has been investigated. The fundamental absorption, which corresponds to electron excitation from the valence band to conduction band, can be used to determine the nature and value of the band gap. The band gap value $E_{\mathrm{g}}$ can be determined by using Tauc's relation [19]: 


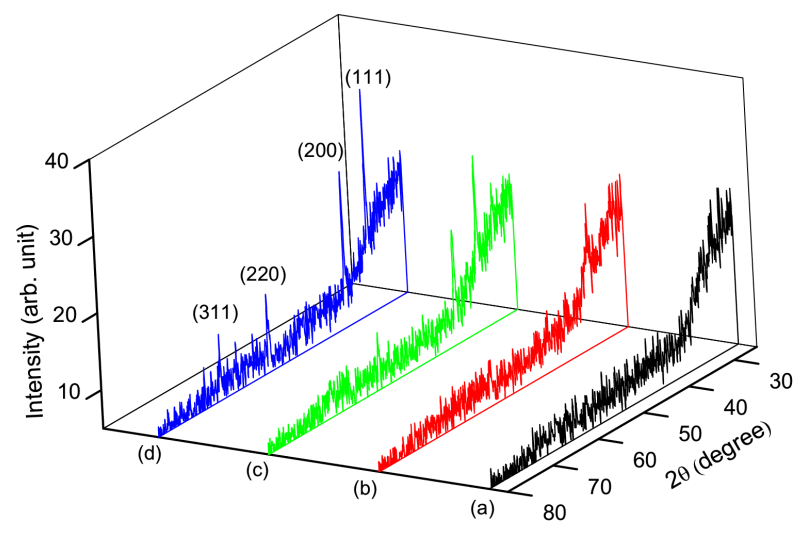

Fig. 1. X-ray diffraction patterns of $\mathrm{CdO}$ thin films: (a) as-deposited, (b) annealed at $200^{\circ} \mathrm{C}$, (c) annealed at $300^{\circ} \mathrm{C}$ and (d) annealed at $400^{\circ} \mathrm{C}$.

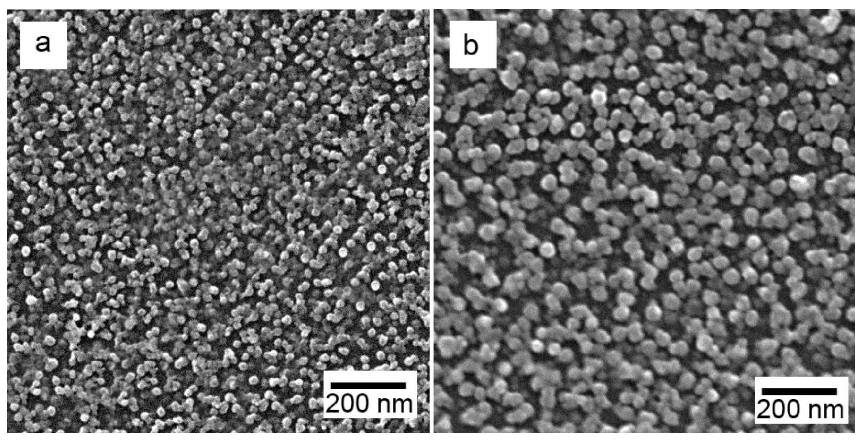

Fig. 2. Typical SEM micrographs of the CdO films annealed at (a) $200^{\circ} \mathrm{C}$, (b) $400^{\circ} \mathrm{C}$.

$$
(\alpha h \nu)=A\left(h \nu-E_{\mathrm{g}}\right)^{n},
$$

where $\alpha$ is the absorption coefficient, $h \nu$ is the photon energy, $A$ is a constant and $n$ assumes the values $0.5,2$, 1.5 and 3 for allowed direct, allowed indirect, forbidden direct, and forbidden indirect transitions, respectively.

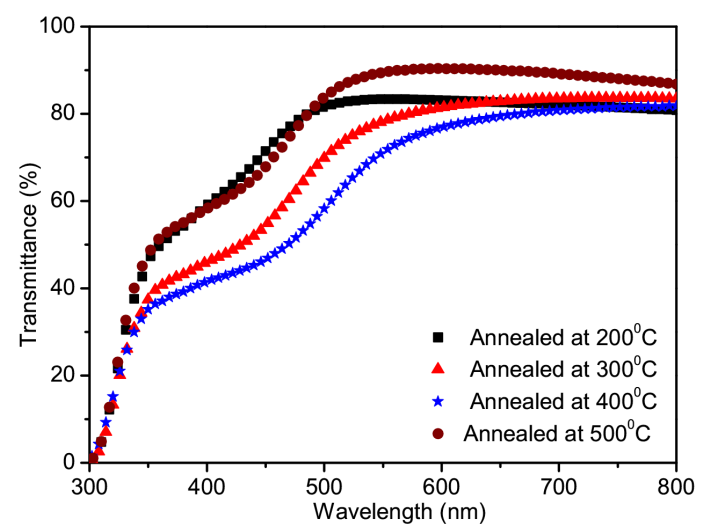

Fig. 3. UV-vis spectra of $\mathrm{CdO}$ thin films annealed at different temperatures.

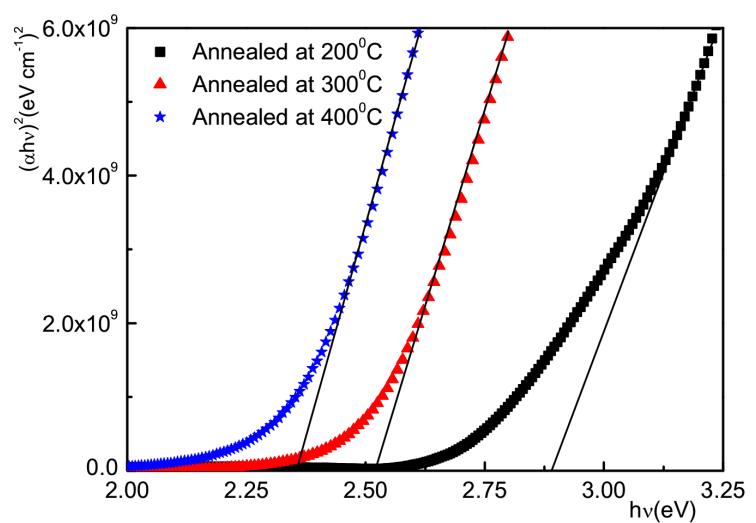

Fig. 4. The plots of $(\alpha \hbar \nu)^{2}$ vs. $h \nu$ for CdO thin films.

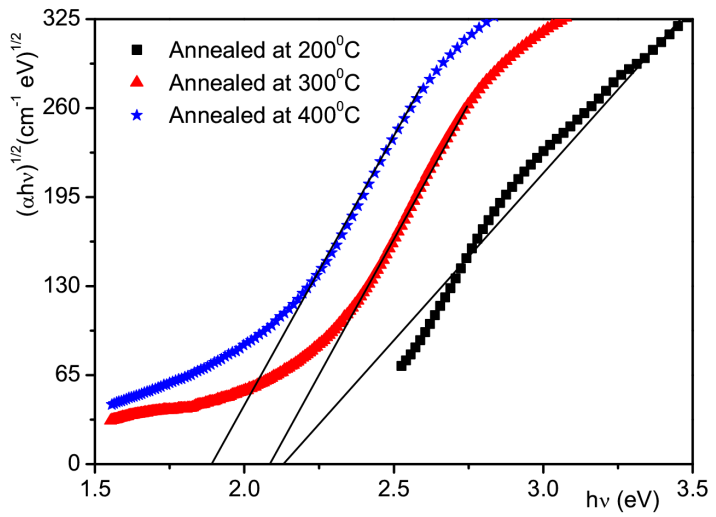

Fig. 5. The plots of $(\alpha \hbar \nu)^{2}$ vs. $h \nu$ for CdO thin films.

Figures 4 and 5 show the variation of $(\alpha h \nu)^{2}$ and $(\alpha h \nu)^{1 / 2}$ versus $h \nu$ for direct and indirect transitions of the $\mathrm{CdO}$ thin films, respectively. The direct band gap $E_{\mathrm{gd}}$ and indirect band gap $E_{\text {gi }}$ values have been determined by the extrapolation of the linear portion on the energy axis as shown in Figs. 4 and 5 , respectively. It can be seen that the value of $E_{\mathrm{gd}}\left(E_{\mathrm{gi}}\right)$ decreased from $2.89 \mathrm{eV}(2.09 \mathrm{eV})$ to $2.35 \mathrm{eV}(1.89 \mathrm{eV})$ as the annealing temperature increased from 200 to $400{ }^{\circ} \mathrm{C}$.

The obtained band gap values are given in Table II. The absorption coefficient $\alpha$ near the fundamental absorption edge usually shows simple exponential energy dependence

$$
\alpha=\alpha_{0} \exp \left(h v / E_{\mathrm{U}}\right)
$$

referred to as the Urbach tail [20], where $\alpha$ is constant and $E_{\mathrm{U}}$ determines the width of the tail. The tail, i.e. the Urbach energy, is generally attributed to disorder in the material that leads to a tail in the valence and conduction bands.

Figure 6 shows the variation of $\ln \alpha$ vs. $h \nu$ for the $\mathrm{CdO}$ films. From the slopes of the linear relationship between $\ln \alpha$ and $h \nu$ in the tail region (Fig. 6), the $E_{\mathrm{U}}$ value for $\mathrm{CdO}$ films was estimated, and the results are given in 


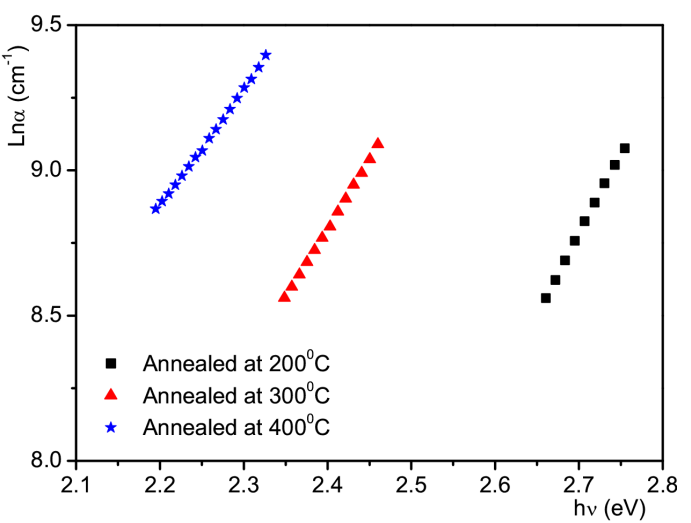

Fig. 6. The plots of $\ln \alpha$ vs. $h \nu$ for $\mathrm{CdO}$ films.

TABLE II

The thickness, direct and indirect band gap $\left(E_{\mathrm{gd}}\right.$ and $E_{\mathrm{gi}}$, respectively) and the Urbach energy $\left(E_{\mathrm{U}}\right)$ values of $\mathrm{CdO}$ thin films prepared at different annealing temperatures.

\begin{tabular}{c|c|c|c|c}
\hline \hline $\begin{array}{c}\text { Annealing } \\
\text { temperature } \\
{\left[{ }^{\circ} \mathrm{C}\right]}\end{array}$ & $\begin{array}{c}\text { Thickness } \\
{[\mathrm{nm}]}\end{array}$ & $E_{\mathrm{gd}}[\mathrm{eV}]$ & $E_{\mathrm{gi}}[\mathrm{eV}]$ & $E_{\mathrm{U}}[\mathrm{eV}]$ \\
\hline 200 & 140 & 2.89 & 2.13 & 0.180 \\
300 & 135 & 2.52 & 2.09 & 0.212 \\
400 & 139 & 2.35 & 1.89 & 0.250
\end{tabular}

Table II. It can be found from the results that the $E_{\mathrm{U}}$ values change inversely with direct optical band gaps of the films. The optical band gap of the films decreased with the increasing annealing temperature. This shift may be attributed to the changes of the quality of the $\mathrm{CdO}$ film with increasing the annealing temperature. After annealing temperature increases, thermal induced defects increase dramatically. This could result in an evident redshift of the optical absorption edge with increasing the annealing temperature. The refractive index $n$ and the

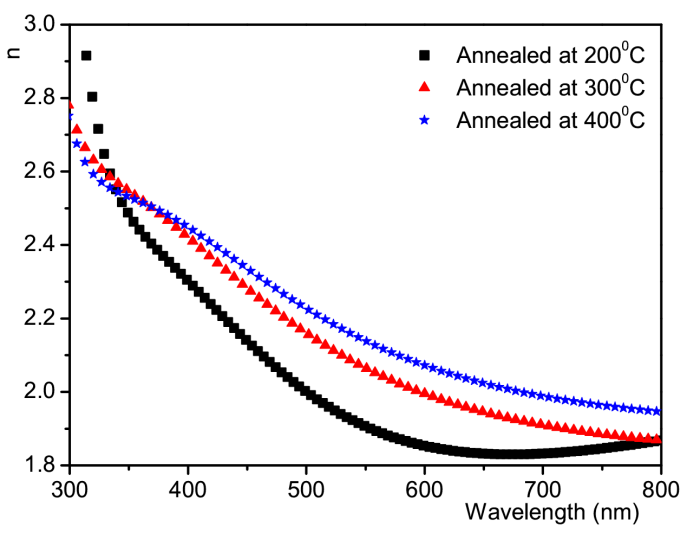

Fig. 7. The dependence of the refractive index of $\mathrm{CdO}$ thin films annealed at different temperatures on the wavelength.

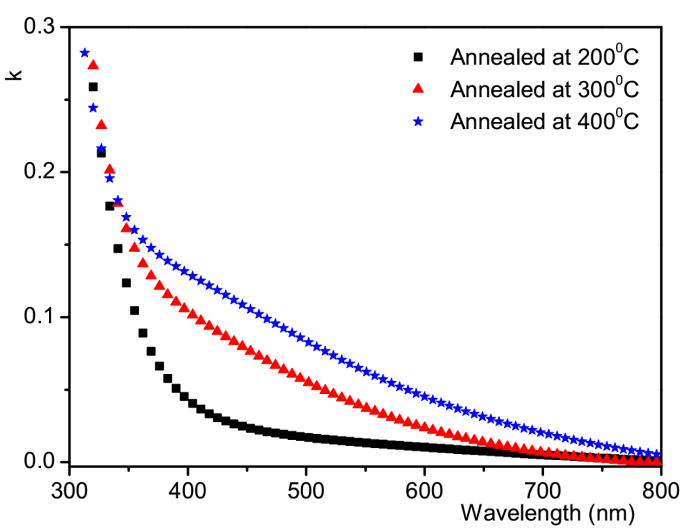

Fig. 8. The dependence of the extinction coefficient of $\mathrm{CdO}$ thin films annealed at different temperatures on the wavelength.

extinction coefficient $k$ as well as the thickness of the solgel derived $\mathrm{CdO}$ thin films studied here were determined from the transmittance data only using PUMA approach and software [15]. This method implements the complex optical equations, shown below, derived and formulated by Heavens [21] and Swanepoel [22]. The transmittance $T$ of a thin absorbing film deposited on a thick transparent substrate is given by

$$
T=\frac{A x}{B-C x+D x^{2}},
$$

where $A=16 n_{\mathrm{s}}\left(n^{2}+k^{2}\right), B=\left[(n+1)^{2}+k^{2}\right][(n+1)(n+$ $\left.\left.n_{\mathrm{s}}^{2}\right)+k^{2}\right], C=\left[\left(n^{2}-1+k^{2}\right)\left(n^{2}-n_{\mathrm{s}}^{2}+k^{2}\right)-2 k^{2}\left(n_{\mathrm{s}}^{2}+\right.\right.$ 1) $] 2 \cos \varphi-k\left[2\left(n^{2}-n_{\mathrm{s}}^{2}+k^{2}\right)+\left(n_{\mathrm{s}}^{2}+1\right)\left(n^{2}-1+k^{2}\right)\right] 2 \sin \varphi$, $D=\left[(n-1)^{2}+k^{2}\right]\left[(n-1)\left(n-n_{\mathrm{s}}^{2}\right)+k^{2}\right], \varphi=4 \pi n d / \lambda$, $x=\exp (-\alpha d)$ and $\alpha=4 \pi k / \lambda$, where $n_{\mathrm{s}}$ is the refractive index of the substrate, $n$ and $k$ are the real and imaginary parts of the refractive index of the film, respectively, $d$ is the film thickness, $\lambda$ is the wavelength of the incident light and $\alpha$ is the absorption coefficient of the film. In PUMA, the experimental transmittance obtained for the film is compared with a theoretical value. The difference between the two values is minimized until a best solution is reached for the refractive index $n$, the extinction coefficient $k$ and the film thickness $d$. This method is highly reliable even in the case of absorbing films or of films that show no fringe pattern in their optical transmission [23].

Figure 7 shows the dependence of the refractive index of the films on wavelength. The refractive index of all samples lies between 1.8 and 2.8 and increases as annealing temperature increases. This trend can be attributed to the increase of optical absorption in the UV-visible region when increasing annealing temperature. The dispersion curve of refractive index is almost constant in the long wavelength region and rises rapidly toward shorter wavelengths. Electromagnetic waves with short (long) wavelengths are dispersed by electron (phonon). This is the typical shape of dispersion curve near an electronic interband transition. This suggests that the films show normal dispersion. 
Figure 8 shows the dependence of extinction coefficient of the films on wavelength. It is changed between 0.00024 and 0.28 and also is fairly constant in the long wavelength. The extinction coefficient of the films has an inverse relation with the transmittance spectra. The high (low) transmittance means low (high) extinction coefficient.

\section{Conclusion}

$\mathrm{CdO}$ thin films were deposited on glass substrates by sol-gel dip-coating method using a different solution. By introducing the diethanolamine as the stabilizer the variation of the structural, morphological and optical properties of the films was investigated as a function of annealing temperature. The structural investigation revealed that the films are polycrystalline. This result along with the SEM images showed that the crystallinity of the films was improved by annealing temperature. The optical properties of the $\mathrm{CdO}$ films were influenced by annealing temperature. The optical band gap values were found to decrease from 2.89 to $2.35 \mathrm{eV}$ for direct transitions and from 2.09 to $1.89 \mathrm{eV}$ for indirect transitions with annealing temperature. Studying the Urbach tail of the samples revealed an increase of disorders in the samples by annealing temperature up to $400^{\circ} \mathrm{C}$. The optical constants, refractive index and extinction coefficient of the films were determined using pointwise unconstrained minimization algorithm. Annealing temperature affects the optical constants of the films.

\section{Acknowledgments}

The authors are grateful to the Islamic Azad University of Lahijan for financial supports.

\section{References}

[1] J. Nishino, T. Kawarada, S. Ohisho, K. Maruyama, K. Kamata, J. Mater. Sci. Lett. 16, 629 (1997).

[2] M. Ritala, T. Asikanen, M. Leskelä, J. Skarp, Mater. Res. Soc. Symp. Proc. 426, 513 (1996).

[3] R. Wang, L.L.H. King, W.W. Sleight, J. Mater. Res. 11, 1659 (1996).
[4] M. Ortega, G. Santana, A. Morales-Acevedo, Solid State Electron. 44, 1765 (2000).

[5] R. Ferro, J.A. Rodríguez, Sol. Energy Mater. Sol. Cells 64, (200) 363.

[6] T.K. Subramanyam, S. Uthanna, B. Srinivasulu Naidu, Mater. Lett. 35, 214 (1998).

[7] O. Vigil, F. Cruz, A. Morales-Acevedo, G. Contreras-Puente, L. Vaillant, G. Santana, Mater. Chem. Phys. 68, 249 (2001).

[8] T.L. Chu, S.S. Chu, J. Electrochem. Soc. 110, 548 (1963).

[9] H. Hobert, B. Seltmann, J. Non-Cryst. Solids 195, 54 (1996).

[10] B. Saha, S. Das, K.K. Chattopadhyay, Sol. Energy Mater. Sol. Cells 91, 1692 (2007).

[11] S. Aksoy, Y. Caglar, S. Ilican, M. Caglar, Int. J. Hydrogen Energy 34, 5191 (2009).

[12] J.S. Cruz, G.T. Delgado, R.C. Perez, S.J. Sandoval, O.J. Sandoval, C.I. Romero, J.M. Marín, O.Z. Angel, Thin Solid Films 493, 83 (2005).

[13] S. Ilican, M. Caglar, Y. Caglar, F. Yakuphanoglu, Optoelecron. Adv. Mater.-Rapid Commun. 3, 135 (2009).

[14] F. Yakuphanoglu, Appl. Surf. Sci. 257, 1413 (2010).

[15] E.G. Birgin, I. Chambouleyron, J.M. Martínez, J. Comput. Phys. 151, 862 (1999).

[16] Q. Peng, G.W. Cong, S.C. Qu, Z.G. Wang, Nanotechnology 16, 1469 (2005).

[17] B.D. Cullity, Elements of X-ray Diffractions, Addison-Wesley, Reading, MA 1978, p. 102.

[18] D.M. Carballeda-Galicia, R. Castanedo-Pérez, O. Jiménez-Sandoval, S. Jiménez-Sandoval, G. Torres-Delgado, C.I. Zúñiga-Romero, Thin Solid Films 371, 105 (2000).

[19] D.R. Sahu, Microchem. J. 38, 1252 (2007).

[20] F. Urbach, Phys. Rev. 92, 1324 (1953).

[21] O.S. Heavens, Optical Properties of Thin Films, Dover, New York 1991.

[22] R. Swanepoel, J. Phys. E, Sci. Instrum. 16, 1214 (1983).

[23] M. Mulato, I. Chambouleyron, E.G. Brigin, J.M. Martinez, Appl. Phys. Lett. 77, 2133 (2000). 